CLINICAL STUDY

\title{
Metformin inhibits goitrogenous effects of type 2 diabetes
}

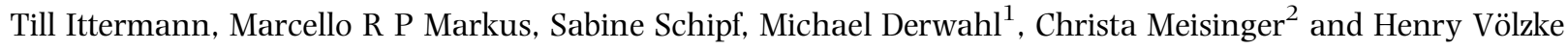 \\ Institute for Community Medicine, University of Greifswald, Greifswald, Germany, ${ }^{1}$ Division of Endocrinology, Department of Medicine, \\ St Hedwig Hospital, Berlin, Germany and ${ }^{2}$ Institute of Epidemiology II, Helmholtz Zentrum München, German Research Center for Environmental Health, \\ München, Germany \\ (Correspondence should be addressed to T Ittermann who is now at Institute for Community Medicine, Ernst Moritz Arndt University, Walther Rathenau \\ Street 48, D-17487 Greifswald, Germany; Email: till.ittermann@uni-greifswald.de)
}

\begin{abstract}
Objective: Data on the association between type 2 diabetes mellitus (T2DM) and thyroid volume are sparse. An experimental study demonstrated an inhibitory effect of metformin on the growth of human thyroid cells. So far no study on humans has investigated potentially modulating effects of metformin on the association between T2DM and thyroid volume. Therefore, we investigated these effects in a population-based cohort study.

Design and methods: We used data from the Study of Health in Pomerania and included 2570 individuals for cross-sectional and 1088 individuals for longitudinal analyses. T2DM was defined by physician-diagnosed self-report or intake of antidiabetic medication.

Results: In the cross-sectional data, females with T2DM treated with antidiabetic medication other than metformin had a larger thyroid volume $(\beta=4.69 ; 95 \%$ CI 1.87 to 7.50$)$ and a higher odds ratio $(\mathrm{OR})$ for goiter $(\mathrm{OR}=1.71 ; 95 \%$ CI 1.05 to 2.79$)$ than females without T2DM, whereas in males, no such association was detected. In females or males treated with metformin, T2DM was not associated with thyroid volume or goiter. In longitudinal analyses, incident T2DM not treated with metformin was significantly associated with a higher risk for incident goiter in the total population (incidence rate ratio $($ IRR $)=1.70 ; 95 \%$ CI 1.10 to 2.91 ). Individuals with T2DM having changed from metformin to other antidiabetic agents during follow-up also had a higher risk for incident goiter than individuals without T2DM (IRR $=2.71 ; 95 \%$ CI 1.74 to 4.20$)$.

Conclusions: We demonstrate an inhibitory effect of metformin on prevalent and incident goiter. Antigoitrogenous effects of metformin add to the general benefits of metformin treatment of T2DM.
\end{abstract}

European Journal of Endocrinology 169 9-15

\section{Introduction}

Metformin is an antidiabetic drug, which is frequently prescribed and recommended in patients with type 2 diabetes mellitus (T2DM), obesity, insulin resistance, hyperinsulinemia, and without kidney disease (1). Metformin reduces more than one third of the total glucose production in T2DM (2) via inhibition of glucose production in the liver (3). Moreover, previous studies demonstrated that all-cause mortality $(4,5)$ is lower in patients with T2DM taking metformin than in those taking other antidiabetic agents. Likewise, it has been shown that metformin decreases lipid levels and does not increase body weight $(3,6)$. Although there are many benefits of metformin treatment, unintended side effects have to be considered. Particularly, metformin is associated with a higher risk for gastrointestinal events such as diarrhea $(7,8)$.

Recently, a few studies revealed possible effects of metformin treatment on thyroid-related characteristics. While three studies in patients with hypothyroidism and/or levothyroxine treatment showed a reduction of serum TSH levels under metformin treatment $(9,10,11)$, a retrospective study demonstrated significantly higher serum TSH levels in euthyroid patients with T2DM treated with metformin compared with those treated with other diabetic agents (12). However, in that study, metformin use was not associated with serum TSH levels after adjustment for several potential confounding factors of which goiter was the only significant one (12). Thus, goiter might explain the difference in serum TSH levels between patients treated with and without metformin, which vice versa might argue for metformin as an independent protective factor for goiter in T2DM.

Data on the association between T2DM and thyroid volume are sparse. A current case-control study with 111 women reported a positive association between insulin resistance and thyroid volume (13). However, that study (13) did not explicitly focus on T2DM and also did not consider antidiabetic drug intake. Focusing on the relationship between metformin and thyroid volume, a recent experimental study (14) demonstrated an inhibitory effect of metformin on the growth of 
human thyroid cells. Thus, it is intriguing to hypothesize that an association between T2DM and goiter, if existent, might be modulated by metformin use. Supporting this note, a study on 66 females with insulin resistance demonstrated a reduction of thyroid nodule size after treatment with metformin (15). So far no study has investigated potentially modulating effects of metformin on the association of T2DM with thyroid volume in the general population. Therefore, we aim to investigate these effects using data from a populationbased German cohort study, in which T2DM was not only defined by physician-diagnosed self-report and medication but also by $\mathrm{HbA1c}$ levels.

\section{Materials and methods}

\section{Study population}

The Study of Health in Pomerania (SHIP) is a population-based cohort study conducted in West Pomerania (16). As with the whole of Germany, the region was formerly iodine deficient until the mid1990s, when an iodine fortification program became effective (17). Particularly among older persons, goiter prevalence is still high (18).

A sample from the population aged 20-79 years was drawn from population registries comprising 6267 eligible subjects. Examinations were performed between 1997 and 2001. The baseline SHIP population (SHIP-0) included 4308 Caucasian participants (response 68.8\%). Between 2002 and 2006, all participants were re-invited for an examination follow-up (SHIP-1), in which 3300 subjects took part (1589 men and 1711 women; $83.5 \%$ of all eligible subjects). The median follow-up time was 5.0 years (minimum, 4.4 years; maximum, 8.6 years; 17315 person-years). Exclusion criteria for the present analyses are presented in Fig. 1.

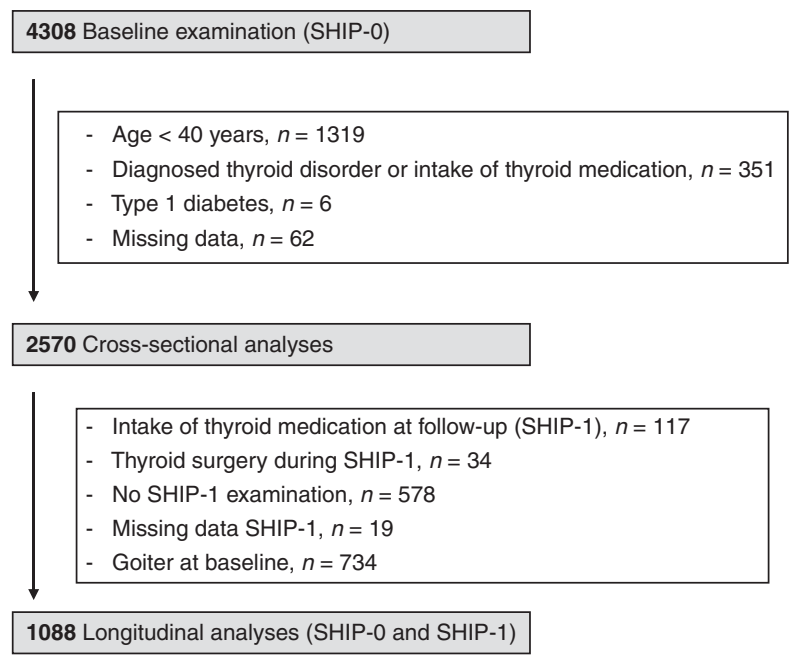

Figure 1 Flow diagram for selection of our study population.
All participants gave informed written consent. The study followed the recommendations of the Declaration of Helsinki and was approved by the Ethics Committee of the University of Greifswald.

\section{Assessments}

Age, sex, smoking status, drug intake, and T2DM were assessed by computer-assisted personal interviews performed by certified staff. Smoking status was categorized into the three categories: current smokers, former smokers, and never smokers. Former smokers were individuals who had smoked during their lifetime but not in the last 12 months before the time of examination. All participants were asked to bring all medications taken 7 days before the time of examination. Medication data were obtained online using the IDOM program (online drug database led medication assessment) and categorized according to the Anatomical Therapeutical Chemical (ATC) classification index. Thyroid medication was defined by the ATC code $\mathrm{HO3}$, antidiabetic medication by the ATC code A10, and metformin intake by the ATC code A10BA02. T2DM was defined by self-reported diabetes in the interview or intake of antidiabetic medication. Individuals with T2DM were further categorized into the two groups: 'metformin intake' and 'no metformin intake'. For the longitudinal analyses, we defined a T2DM variable with seven levels: 1) no T2DM in SHIP-0 and SHIP-1; 2) no T2DM in SHIP-0, but T2DM not treated with metformin in SHIP-1; 3) no T2DM in SHIP-0, but T2DM treated with metformin in SHIP-1; 4) T2DM not treated with metformin in SHIP-O and SHIP-1; 5) T2DM not treated with metformin in SHIP-0, but treated with metformin in SHIP-1; 6) T2DM treated with metformin in SHIP-0, but not treated with metformin in SHIP-1; and 7) T2DM treated with metformin in SHIP-0 and SHIP-1).

Examinations at baseline and follow-up included anthropometry, thyroid ultrasonography, and laboratory measurements. Height and weight were measured for calculation of the BMI: BMI $=$ weight $(\mathrm{kg}) /$ height $^{2}\left(\mathrm{~m}^{2}\right)$. In SHIP-O and SHIP-1, thyroid ultrasonography was performed with an ultrasound VST-Gateway with a $5 \mathrm{MHz}$ linear array transducer (Diasonics, Santa Clara, CA, USA). Thyroid volume was calculated as length $X$ width $\times$ depth $\times 0.479(\mathrm{ml})$ for each lobe (19). Intra- and inter-observer reliabilities were assessed before the start of SHIP and afterward annually. All measurements of the thyroid volume showed Spearman correlation coefficients of $>0.85$ and mean differences $( \pm 2$ s.D.) of the mean bias $<5 \%(<25 \%)$ between the examiners. Goiter was defined as a thyroid volume of $>18 \mathrm{ml}$ in women and of $>25 \mathrm{ml}$ in men (20). These cutoff values appear rather high but are appropriate given that West Pomerania suffered from iodine deficiency until the mid-1990s (21). Furthermore, we have kept this procedure constant over all publications for more than 10 years (22). 
Although a more modern definition would also be possible, we have not introduced this so far to avoid the impression that goiter is arbitrarily defined across different SHIP publications.

Individuals were classified as having thyroid nodules if at least one thyroid nodule was detected in the right or the left lobe of the thyroid. Serum TSH levels were measured by immunochemiluminescent procedures (SHIP-0: LIA-mat, Byk Sangtec Diagnostica GmbH, Frankfurt, Germany; SHIP-1: Immulite 2000, Third generation, Diagnostic Products Corporation, DPC, Los Angeles, USA). HbA1c levels were measured by HPLC (ClinRep HbA1c, Recipe Chemicals + Instruments GmbH, Munich, Germany) with a coefficient of variation of $1.5 \%$ during SHIP-0.

\section{Statistical analysis}

Data on quantitative characteristics are expressed as median and interquartile range; data on qualitative characteristics are expressed as percentages and absolute numbers. Group comparisons were done by Kruskal-Wallis test (continuous data) and $\chi^{2}$ test (categorical data). Baseline T2DM treated with and without metformin was associated with baseline thyroid volume by linear regression and with prevalent goiter by logistic regression, both adjusted for age, sex, smoking status, and BMI. Analyses were repeated stratified by sex. Furthermore, we repeated the crosssectional analyses in a population excluding individuals with dietary treatment of T2DM and individuals having no diagnosed T2DM but HbA1c levels $\geq 6.5 \%$.

Change in T2DM and antidiabetic medication during follow-up was associated with incident goiter by Poisson regression with robust standard errors weighted for loss to follow-up and adjusted for baseline values of age, sex, smoking status, and BMI and for the log-transformed time between baseline and follow-up. Results of linear regressions are expressed as adjusted means and 95\% CIs, results of the logistic regressions as odds ratio (OR) and $95 \% \mathrm{CI}$, and results of the Poisson regressions as incidence rate ratios (IRR) and 95\% CI. $P<0.05$ was considered as statistically significant. All analyses were performed using Stata 12.1 (Stata Corporation, College Station, TX, USA).

\section{Results}

\section{Cross-sectional results}

There were 278 individuals with T2DM in SHIP-O $(11.0 \%)$ of which 83 subjects $(29.2 \%)$ were treated with metformin. The proportion of males was significantly higher among individuals with T2DM compared with individuals without T2DM (Table 1). Furthermore, individuals with T2DM were older and had a higher BMI and higher serum glucose and HbA1c levels than individuals without T2DM. Age at T2DM onset was comparable between groups of T2DM treated with and without metformin. Thyroid volume and goiter prevalence were the highest in the group of individuals with T2DM not treated with metformin. These differences were more pronounced among females than among males (Table 2). Thyroid nodules were more prevalent in individuals with T2DM, but the prevalence did not differ between individuals with and without metformin treatment (Table 1). Serum TSH levels were similar among individuals with and without T2DM.

Multivariable regression analyses adjusted for age, sex, smoking status, and BMI revealed that females with T2DM not treated with metformin had significantly larger thyroid volumes and a significantly higher risk for goiter than females without T2DM (Table 3). In contrast, females with T2DM treated with metformin

Table 1 Characteristics of the SHIP-0 population stratified by T2DM defined by self-report and medication intake. Data are expressed as median and interquartile range for continuous data and as total numbers and percentages for categorical data.

\begin{tabular}{|c|c|c|c|c|}
\hline & No T2DM $(n=2292)$ & $\begin{array}{l}\text { T2DM and no metformin } \\
\text { intake }(n=195)\end{array}$ & $\begin{array}{l}\text { T2DM and metformin } \\
\text { intake }(n=83)\end{array}$ & $\boldsymbol{P}^{\mathrm{a}}$ \\
\hline Males & $1227(53.5 \%)$ & $120(61.5 \%)$ & $45(54.2 \%)$ & 0.098 \\
\hline Age (years) & $57(48 ; 67)$ & $67(60 ; 74)$ & $64(57 ; 71)$ & $<0.001$ \\
\hline BMI $\left(\mathrm{kg} / \mathrm{m}^{2}\right)$ & $27.6(24.8 ; 30.5)$ & $29.1(26.6 ; 32.3)$ & $30.0(27.5 ; 34.8)$ & $<0.001$ \\
\hline \multicolumn{5}{|l|}{ Smoking status } \\
\hline Former & $886(38.7 \%)$ & $100(51.3 \%)$ & $39(47.0 \%)$ & $<0.001$ \\
\hline Current & $575(25.1 \%)$ & $23(11.8 \%)$ & $9(10.8 \%)$ & \\
\hline Glucose $(\mathrm{mmol} / \mathrm{l})$ & $5.4(5.0 ; 5.9)$ & $7.8(6.2 ; 10.4)$ & $8.6(5.9 ; 10.4)$ & $<0.001$ \\
\hline $\mathrm{HbA1c}(\%)$ & $5.4(5.0 ; 5.8)$ & $7.0(6.1 ; 7.9)$ & $6.9(6.6 ; 8.3)$ & $<0.001$ \\
\hline Diabetic medication & - & $143(73.3 \%)$ & $83(100.0 \%)$ & $<0.001$ \\
\hline Age of T2DM onset & - & $55(48 ; 64)$ & $54(48 ; 60)$ & 0.356 \\
\hline Thyroid volume $(\mathrm{ml})$ & $19.7(14.9 ; 27.0)$ & $23.1(16.4 ; 29.4)$ & $21.0(15.6 ; 28.4)$ & 0.003 \\
\hline Goiter & $953(41.6 \%)$ & $101(51.8 \%)$ & $35(42.2 \%)$ & 0.021 \\
\hline At least one thyroid nodule & $575(25.1 \%)$ & $63(32.3 \%)$ & $27(32.5)$ & 0.033 \\
\hline TSH (mIU/l) (SHIP-0) & $0.62(0.42 ; 0.87)$ & $0.61(0.40 ; 0.89)$ & $0.69(0.49 ; 0.88)$ & 0.359 \\
\hline TSH (mIU/l) (SHIP-1) & $0.73(0.50 ; 1.09)$ & $0.79(0.57 ; 1.14)$ & $0.80(0.60 ; 1.10)$ & 0.302 \\
\hline
\end{tabular}

T2DM, type 2 diabetes mellitus.

a Kruskal-Wallis test (continuous data) and $\chi^{2}$ test (categorical data). 
Table 2 Characteristics of the SHIP-0 population stratified by sex and by T2DM defined by self-report and medication intake. Data are expressed as median and interquartile range for continuous data and as total numbers and percentages for categorical data.

\begin{tabular}{|c|c|c|c|c|}
\hline & No T2DM $(n=2292)$ & $\begin{array}{l}\text { T2DM and no metformin } \\
\text { intake }(n=195)\end{array}$ & $\begin{array}{l}\text { T2DM and metformin } \\
\text { intake }(n=83)\end{array}$ & $P^{\mathrm{a}}$ \\
\hline \multicolumn{5}{|l|}{ Age (years) } \\
\hline Males & $59(49 ; 68)$ & $67(61 ; 75)$ & $63(56 ; 69)$ & $<0.001$ \\
\hline \multirow{2}{*}{\multicolumn{5}{|c|}{ BMI $\left(\mathrm{kg} / \mathrm{m}^{2}\right)$}} \\
\hline & & & & \\
\hline Males & $27.9(25.5 ; 30.2)$ & $29.1(26.7 ; 31.6)$ & $30.0(27.4 ; 34.1)$ & $<0.001$ \\
\hline Females & $27.2(24.0 ; 30.7)$ & $29.8(26.1 ; 33.1)$ & $30.0(27.7 ; 35.5)$ & $<0.001$ \\
\hline \multicolumn{5}{|c|}{ Current smokers } \\
\hline Males & 350 (28.5\%) & $16(13.3 \%)$ & $7(15.6 \%)$ & $<0.001$ \\
\hline Females & 225 (21.1\%) & $7(9.3 \%)$ & $2(5.3 \%)$ & 0.011 \\
\hline \multicolumn{5}{|c|}{ Former smokers } \\
\hline Males & 643 (52.4\%) & 85 (70.8\%) & $29(64.4 \%)$ & $<0.001$ \\
\hline Females & 243 (22.8\%) & 15 (20.0\%) & $10(26.3 \%)$ & 0.480 \\
\hline \multicolumn{5}{|c|}{ Glucose $(\mathrm{mmol} / \mathrm{l})$} \\
\hline Males & $5.5(5.1 ; 6.0)$ & $8.1(6.4 ; 10.3)$ & $8.5(5.9 ; 10.5)$ & $<0.001$ \\
\hline Females & $5.3(4.9 ; 5.7)$ & $7.6(5.8 ; 10.4)$ & $8.7(6.6 ; 10.3)$ & $<0.001$ \\
\hline \multicolumn{5}{|l|}{$\mathrm{HbA1c}(\%)$} \\
\hline Males & $5.4(5.1 ; 5.9)$ & $7.0(6.1 ; 8.1)$ & $6.9(6.4 ; 8.3)$ & $<0.001$ \\
\hline Females & $5.3(4.9 ; 5.7)$ & $6.9(6.1 ; 7.9)$ & $7.0(6.8 ; 8.2)$ & $<0.001$ \\
\hline \multicolumn{5}{|c|}{ Diabetic medication } \\
\hline Males & - & 87 (72.5\%) & 45 (100.0\%) & $<0.001$ \\
\hline Females & - & 56 (74.7\%) & $38(100.0 \%)$ & $<0.001$ \\
\hline \multicolumn{5}{|c|}{ Thyroid volume (ml) } \\
\hline Males & $23.7(18.4 ; 30.9)$ & $24.8(18.7 ; 30.5)$ & $24.4(19.0 ; 29.2)$ & 0.869 \\
\hline Females & $16.3(12.4 ; 20.7)$ & $19.7(12.8 ; 26.8)$ & $16.6(13.7 ; 26.9)$ & 0.016 \\
\hline \multicolumn{5}{|l|}{ Goiter } \\
\hline Males & 546 (44.5\%) & 59 (49.2\%) & $18(40.0 \%)$ & 0.499 \\
\hline Females & 407 (38.2\%) & $42(56.0 \%)$ & $17(44.7 \%)$ & 0.008 \\
\hline
\end{tabular}

T2DM, type 2 diabetes mellitus.

${ }^{a}$ Kruskal-Wallis test (continuous data) and $\chi^{2}$ test (categorical data).

had no significantly higher thyroid volumes and no significantly higher risk for goiter than females without T2DM. In males with and without T2DM, no significant differences in thyroid volume or goiter prevalence were detected.

After exclusion of individuals with T2DM treated only by diet, females with T2DM not treated with metformin still had a significantly larger thyroid volume $(\beta=4.58$; $95 \%$ CI 1.47 to $7.68 ; P=0.004)$ and a significantly higher OR for goiter $(\mathrm{OR}=2.25$; 95\% CI 1.27 to 3.99; $P=0.005)$ than females without T2DM, whereas females with T2DM treated with metformin had no significantly larger thyroid volume $(\beta=0.77 ; 95 \% \mathrm{CI}$ -3.02 to $4.55 ; P=0.690)$ and no significantly higher OR for goiter $(\mathrm{OR}=1.09 ; 95 \%$ CI 0.55 to 2.16$)$ than females without T2DM. Similar to the whole male population, no associations were detected between T2DM and thyroid size.

Further exclusion of individuals with an $\mathrm{HbAlc}$ $\geq 6.5 \%$ who were not aware of their T2DM $(n=103 ; 70$ males) increased the effect sizes in the group with T2DM not treated with metformin. In women, the effect sizes were $\beta=4.65$ (95\% CI 1.53 to $7.78 ; P=0.004)$ for thyroid volume and $\mathrm{OR}=2.32(95 \%$ CI 1.31 to 4.11 ; $P=0.004$ ) for prevalent goiter. Males with T2DM not treated with metformin had no significant larger thyroid volume $(\beta=0.34 ; 95 \% \mathrm{CI}-2.28$ to $2.96 ; P=0.800)$ and no significant higher $\mathrm{OR}$ for goiter $(\mathrm{OR}=1.32 ; 95 \%$ CI 0.84 to $2.07 ; P=0.236$ ) than males without $\mathrm{T} 2 \mathrm{DM}$, but effect sizes were higher than in the main analyses.

Table 3 Association between baseline T2DM (defined by self-report and medication intake) with and without metformin intake and baseline thyroid volume. Linear regression for thyroid volume and logistic regression for goiter adjusted for age, sex, smoking status, and BMI.

\begin{tabular}{|c|c|c|c|c|c|c|}
\hline & \multicolumn{3}{|c|}{ Thyroid volume $(\mathrm{ml})$ (adjusted means $(95 \% \mathrm{Cl}))$} & \multicolumn{3}{|c|}{ Goiter (odds ratio $(95 \% \mathrm{Cl}))$} \\
\hline & No T2DM & $\begin{array}{l}\text { T2DM and no } \\
\text { metformin intake }\end{array}$ & $\begin{array}{c}\text { T2DM and } \\
\text { metformin intake }\end{array}$ & No T2DM & $\begin{array}{l}\text { T2DM and no } \\
\text { metformin intake }\end{array}$ & $\begin{array}{c}\text { T2DM and } \\
\text { metformin intake }\end{array}$ \\
\hline All & $22.5(22.1 ; 23.0)$ & $24.2(22.5 ; 25.9)$ & $22.2(19.6 ; 24.7)$ & Reference & $1.35(1.00 ; 1.83)$ & $0.89(0.57 ; 1.41)$ \\
\hline Males & $26.0(25.4 ; 26.7)$ & $25.8(23.7 ; 27.9)$ & $24.8(21.4 ; 28.2)$ & Reference & $1.16(0.79 ; 1.71)$ & $0.76(0.41 ; 1.41)$ \\
\hline Females & $18.4(17.7 ; 19.1)$ & $23.1^{\dagger}(20.4 ; 25.8)$ & $19.0(15.2 ; 22.7)$ & Reference & $1.71^{*}(1.05 ; 2.79)$ & $1.03(0.52 ; 2.02)$ \\
\hline
\end{tabular}

T2DM, type 2 diabetes mellitus. ${ }^{\star} P<0.05 ;{ }^{\dagger} P<0.001$. 


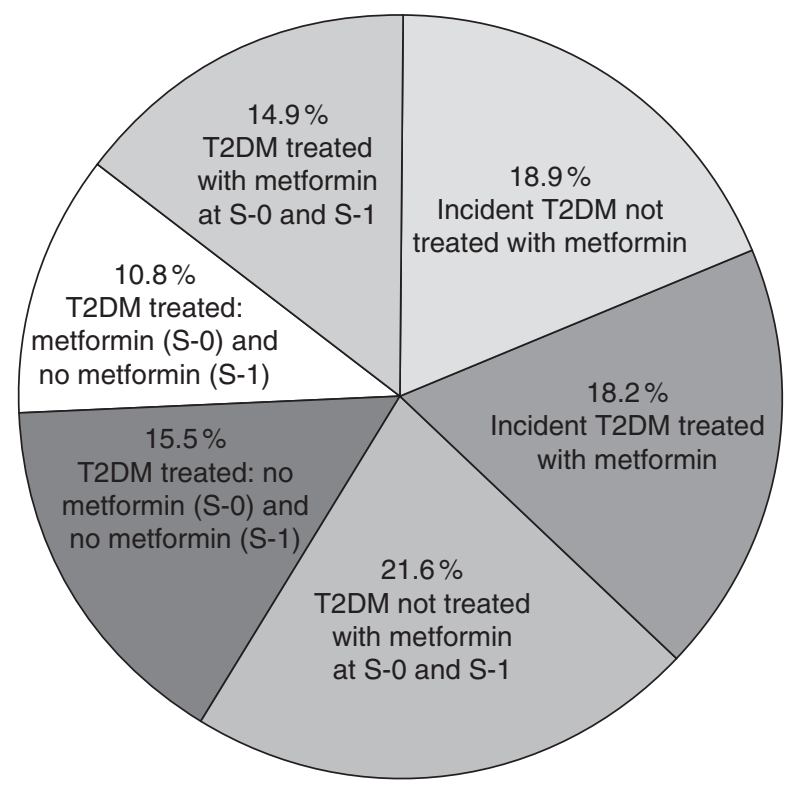

Figure 2 Individuals with type 2 diabetes mellitus (T2DM) at followup stratified by metformin treatment at baseline and follow-up.

\section{Longitudinal results}

Thyroid volume increased in median by $1.3 \mathrm{ml}$ (interquartile range $=-0.9$ to 4.0 ) between SHIP-O and SHIP-1. Incidence of goiter was $22.4 \%$. Fifty-five individuals developed T2DM during SHIP-1 corresponding to an incidence of $5.5 \%$. Incidence of T2DM was higher in males than in females (6.5 vs $4.5 \%)$. In total, there were 148 individuals with T2DM at SHIP-1 (13.6\%). Proportions of metformin treatment in individuals with T2DM at SHIP-1 are shown in Fig. 2.

In multivariable Poisson regression, incident T2DM not treated with metformin was positively associated with incident goiter $(P=0.020$; Fig. 3). Moreover, individuals with T2DM at SHIP-O and SHIP-1 switching from metformin to other antidiabetic agents during follow-up had a higher risk for incident goiter than individuals without T2DM at SHIP-0 and SHIP-1 $(P<0.001)$. Because of the relatively low numbers included in our longitudinal analyses, it was not useful to perform sex-stratified analyses.

\section{Discussion}

In our cross-sectional data, we demonstrated a significant association between T2DM and thyroid volume in women not treated with metformin. This association was still present after exclusion of all women whose T2DM was treated with diet. These findings are in agreement with a small study from Argentina conducted in 133 women (13), in which insulin resistance was associated with thyroid volume, independently of obesity. Our study not only confirms the results of that study
(13) but also enhances recent knowledge by adding evidence that the association between T2DM and thyroid volume is not only present in selected volunteers but also in a general population from Central Europe. Furthermore, Northeast Germany is a region with former mild-to-moderate iodine deficiency (21), while the Argentinian study (13) was conducted in a region with sufficient iodine supply (23). The fact that two studies from regions with different iodine supplies came to similar conclusions may argue for a real association between T2DM and thyroid volume.

While thyroid volume was larger in females with T2DM treated with diet or medication other than metformin, there was no such association in females with T2DM treated with metformin. This finding is in good agreement with the results of an experimental study (14), in which an inhibitory effect of metformin on the growth of thyroid cells derived from nodular goiters was demonstrated. Metformin directly inhibits thyroid growth by activation of the AMPK/mammalian target of rapamycin (mTOR) pathway and antagonized the growth-stimulatory effect of insulin by inhibition of the MAPK pathway (14). Furthermore, in T2DM, metformin reduces insulin resistance and in turn hyperinsulinemia mainly by decreasing gluconeogenesis in the liver (24). This contributes to a diminished growth stimulation of the thyroid gland.

In contrast to our results in females, there was no association between T2DM and thyroid volume in males not treated with metformin. The reason for this discrepancy might be referred to a misclassification of T2DM in males. Females consult physicians more frequently and earlier than males (25), which might have led to a higher detection rate of T2DM in females. As a consequence, we might have underestimated the total number of males with T2DM in our cross-sectional population because T2DM was defined as a self-reported

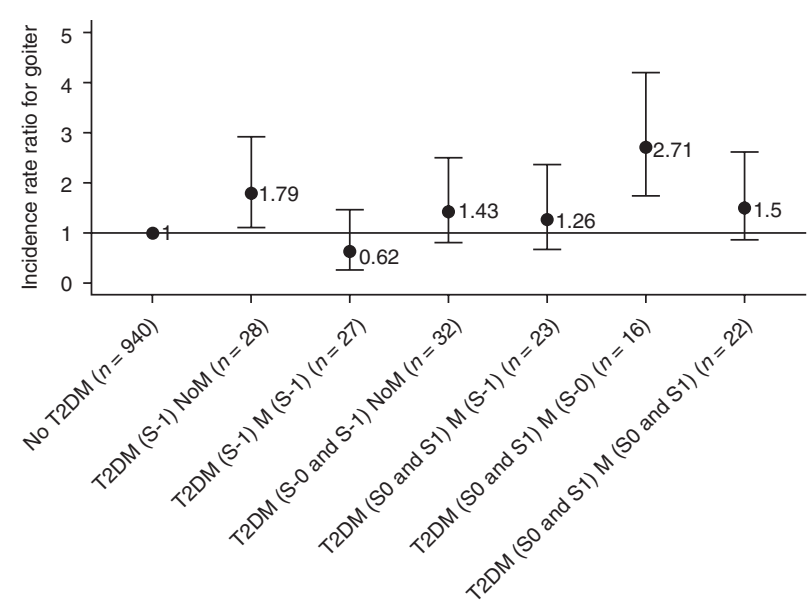

Figure 3 Association of change in incident type 2 diabetes mellitus (T2DM) and antidiabetic treatment with incident goiter. NoM, no metformin treatment; M, metformin treatment; S-0, baseline examination; S-1, follow-up examination. 
diagnosis by a physician. Indeed, the frequency of HbA1c levels $\geq 6.5 \%$, a threshold for T2DM according to guidelines of the American Diabetes Association in $2010(25,26)$, was significantly higher in males than in females after excluding individuals with self-reported T2DM. Furthermore, the association between T2DM not treated with metformin and thyroid volume was stronger when individuals without previous selfreported $\mathrm{T} 2 \mathrm{DM}$ but an $\mathrm{HbA} 1 \mathrm{c} \geq 6.5 \%$ were excluded from analyses. Thus, the group of males without diagnosed T2DM might be more heterogeneous than the respective group of females, which might partly explain the conflicting results between the sexes.

Another explanation for the different results between the sexes might have resulted from different smoking habits in males and females. In SHIP, the frequency of former smokers was higher in males with T2DM than in those without, while this was not the case for females (27). Furthermore, we have shown that smoking was positively associated with prevalent goiter in SHIP (28). Thus, smoking might have diminished the protective effect of metformin on the association between T2DM and goiter, particularly in males.

In agreement with the results of our cross-sectional data, individuals with T2DM not treated with metformin had a higher risk for incident goiter than individuals without T2DM, whereas this was not the case for individuals with T2DM treated with metformin. This finding provides further evidence that metformin inhibits thyroid growth and indicates that patients with T2DM and concomitant goiter should be preferably treated with metformin. Future randomized controlled trials should address the protective effect of metformin against the development of goiter.

Strengths of our study are its population-based design and the standardized protocol of thyroid ultrasonography, which was certified regularly during the study. A further strength of our study is that T2DM was not only defined by self-report but also by $\mathrm{HbA1c}$ levels. A limitation of our study is that some groups in the longitudinal analyses had relatively low numbers, so that it was not possible to perform sex-stratified analyses and it might be that we do not have sufficient power to demonstrate significant effects for risk ratios of 1.5. A further limitation of our study is the lack of information on insulin resistance.

We demonstrate an inhibitory effect of metformin on prevalent and incident goiter. Anti-goitrogenous effects of metformin add to the general benefits of metformin treatment in T2DM. This is of particular relevance for populations from regions with current or former iodine deficiency, where goiter is a highly prevalent finding.

\section{Declaration of interest}

The authors declare that there is no conflict of interest that could be perceived as prejudicing the impartiality of the research reported.

\section{Funding}

SHIP is part of the Community Medicine Net (http://www.medizin. uni-greifswald.de/cm) of the University of Greifswald, which is funded by grants from the German Federal Ministry of Education and Research (BMBF, grant 01ZZ0403); the Ministry for Education, Research, and Cultural Affairs; and the Ministry for Social Affairs of the Federal State of Mecklenburg - West Pomerania. The analyses were further supported by the German Research Foundation (DFG Vo 955/5-2) and the Competence Network of Diabetes.

\section{References}

1 Task Force of the International Diabetes Federation. Global Guideline for Type 2 Diabetes: recommendations for standard, comprehensive, and minimal care. Diabetic Medicine 200623 579-593. (doi:10.1111/j.1464-5491.2006.01918.x)

2 Hundal RS, Krssak M, Dufour S, Laurent D, Lebon V, Chandramouli V, Inzucchi SE, Schumann WC, Petersen KF, Landau BR et al. Mechanism by which metformin reduces glucose production in type 2 diabetes. Diabetes 200049 2063-2069. (doi:10.2337/diabetes.49.12.2063)

3 Kirpichnikov D, McFarlane SI \& Sowers JR. Metformin: an update. Annals of Internal Medicine 2002137 25-33. (doi:10.7326/00034819-137-1-200207020-00009)

4 UKPDS group. Effect of intensive blood-glucose control with metformin on complications in overweight patients with type 2 diabetes (UKPDS 34). UK Prospective Diabetes Study (UKPDS) Group. Lancet 1998352 854-865. (doi:10.1016/S0140-6736(98)07037-8)

5 Holman RR, Paul SK, Bethel MA, Matthews DR \& Neil HA. 10-Year follow-up of intensive glucose control in type 2 diabetes. New England Journal of Medicine 2008359 1577-1589. (doi:10.1056/NEJMoa0806470)

6 Bolen S, Feldman L, Vassy J, Wilson L, Yeh HC, Marinopoulos S, Wiley C, Selvin E, Wilson R, Bass EB et al. Systematic review: comparative effectiveness and safety of oral medications for type 2 diabetes mellitus. Annals of Internal Medicine 2007147 386-399. (doi:10.7326/0003-4819-147-6-200709180-00178)

7 Kahn SE, Haffner SM, Heise MA, Herman WH, Holman RR, Jones NP, Kravitz BG, Lachin JM, O’Neill MC, Zinman B et al. Glycemic durability of rosiglitazone, metformin, or glyburide monotherapy. New England Journal of Medicine 2006355 2427-2443. (doi:10.1056/NEJMoa066224)

8 Nathan DM, Buse JB, Davidson MB, Ferrannini E, Holman RR, Sherwin R \& Zinman B. Medical management of hyperglycemia in type 2 diabetes: a consensus algorithm for the initiation and adjustment of therapy: a consensus statement of the American Diabetes Association and the European Association for the Study of Diabetes. Diabetes Care 200932 193-203. (doi:10.2337/dc08-9025) 9 Cappelli C, Rotondi M, Pirola I, Agosti B, Formenti A, Zarra E, Valentini U, Leporati P, Chiovato L \& Castellano M. Thyreotropin levels in diabetic patients on metformin treatment. European Journal of Endocrinology 2012167 261-265.

10 Cappelli C, Rotondi M, Pirola I, Agosti B, Gandossi E, Valentini U, De Martino E, Cimino A, Chiovato L, Agabiti-Rosei E et al. TSHlowering effect of metformin in type 2 diabetic patients: differences between euthyroid, untreated hypothyroid, and euthyroid on $\mathrm{L}-\mathrm{T}_{4}$ therapy patients. Diabetes Care 200932 1589-1590. (doi:10.2337/dc09-0273)

11 Vigersky RA, Filmore-Nassar A \& Glass AR. Thyrotropin suppression by metformin. Journal of Clinical Endocrinology and Metabolism 200691 225-227. (doi:10.1210/jc.2005-1210)

12 Diez JJ \& Iglesias P. Relationship between serum thyrotropin concentrations and metformin therapy in euthyroid patients with type 2 diabetes. Clinical Endocrinology $2012 \mathbf{7 8}$ 505-511. (doi:10.1111/j.1365-2265.2012.04468.x)

13 Rezzonico J, Rezzonico M, Pusiol E, Pitoia F \& Niepomniszcze H. Introducing the thyroid gland as another victim of the insulin resistance syndrome. Thyroid 2008 18 461-464. (doi:10.1089/ thy.2007.0223) 
14 Chen G, Xu S, Renko K \& Derwahl M. Metformin inhibits growth of thyroid carcinoma cells, suppresses self-renewal of derived cancer stem cells, and potentiates the effect of chemotherapeutic agents. Journal of Clinical Endocrinology and Metabolism 201297 E510-E520. (doi:10.1210/jc.2011-1754)

15 Rezzonico J, Rezzonico M, Pusiol E, Pitoia F \& Niepomniszcze H. Metformin treatment for small benign thyroid nodules in patients with insulin resistance. Metabolic Syndrome and Related Disorders 20119 69-75. (doi:10.1089/met.2010.0026)

16 Volzke H, Alte D, Schmidt CO, Radke D, Lorbeer R, Friedrich N, Aumann N, Lau K, Piontek M, Born G et al. Cohort profile: the Study of Health in Pomerania. International Journal of Epidemiology 201140 294-307. (doi:10.1093/ije/dyp394)

17 Völzke H, Lüdemann J, Robinson DM, Spieker KW, Schwahn C, Kramer A, John U \& Meng W. The prevalence of undiagnosed thyroid disorders in a previously iodine-deficient area. Thyroid 200313 803-810. (doi:10.1089/105072503768499680)

18 Meisinger C, Ittermann T, Wallaschofski H, Heier M, Below $\mathrm{H}$, Kramer A, Doring A, Nauck M \& Volzke H. Geographic variations in the frequency of thyroid disorders and thyroid peroxidase antibodies in persons without former thyroid disease within Germany. European Journal of Endocrinology 2012167 363-371. (doi:10.1530/EJE-12-0111)

19 Brunn J, Block U, Ruf G, Bos I, Kunze WP \& Scriba PC. Volumetric analysis of thyroid lobes by real-time ultrasound. Deutsche Medizinische Wochenschrift 1981106 409-414. (doi:10.1055/ s-2008-1070506)

20 Gutekunst R, Becker W, Hehrmann H, Olbricht W \& Pfannenstiel P. Ultrasonic diagnosis of the thyroid gland. Deutsche Medizinische Wochenschrift 1988113 1109-1112. (doi:10.1055/ s-2008-1067777)

21 Meng W \& Scriba P. Jodversorgung in Deutschland, Probleme und erforderliche Maßnahmen: Update [Iodine supply in Germany, problems and required measures: Update 2002]. Deutsches Ärzteblatt 200299 A2560-A2564.
22 Volzke H, Ittermann T, Albers M, Friedrich N, Nauck M, Below H \& Kramer A. Five-year change in morphological and functional alterations of the thyroid gland: the study of health in pomerania. Thyroid 201222 737-746. (doi:10.1089/thy.2011.0525)

23 Saborido L, Latres de Rauek B, Rezzonico JN, Guntsche Z, Cabut V, Leiva R, Munoz P, Bidot L, Vitoria C \& Rosso A. Iodine in school children. Relationship with incidence of goiter, socioeconomic group and salt intake. Medicina $1996 \mathbf{5 6} 448-454$.

24 Shaw RJ, Lamia KA, Vasquez D, Koo SH, Bardeesy N, Depinho RA, Montminy $\mathrm{M} \&$ Cantley LC. The kinase LKB1 mediates glucose homeostasis in liver and therapeutic effects of metformin. Science $2005 \mathbf{3 1 0}$ 1642-1646. (doi:10.1126/ science.1120781)

25 Hazzard WR. Biological basis of the sex differential in longevity. Journal of the American Geriatrics Society 198634 455-471.

26 American Diabetes Association. Executive summary: standards of medical care in diabetes - 2010. Diabetes Care 201033 (Suppl 1) S4-S10.

27 Schipf S, Schmidt CO, Alte D, Werner A, Scheidt-Nave C, John U, Steveling A, Wallaschofski H \& Volzke H. Smoking prevalence in type 2 diabetes: results of the Study of Health in Pomerania (SHIP) and the German National Health Interview and Examination Survey (GNHIES). Diabetic Medicine 200926 791-797. (doi:10. 1111/j.1464-5491.2009.02784.x)

28 Völzke H, Schwahn C, Kohlmann T, Kramer A, Robinson DM, John U \& Meng W. Risk factors for goiter in a previously iodinedeficient region. Experimental and Clinical Endocrinology $\&$ Diabetes $2005113507-515$. (doi:10.1055/s-2005-865741)

Received 1 February 2013

Revised version received 3 April 2013

Accepted 9 April 2013 